\title{
Fibroma periférico odontogénico. A propósito de un caso
}

\section{Peripheral odontogenic fibroma. A case report}

\author{
Rebolledo Cobos $\mathrm{M}^{*}$, Cantillo Payares O**, Díaz Caballero A***
}

\section{RESUMEN}

El fibroma periférico odontogénico es una lesión tumoral de la submucosa oral o del ligamento periodontal causado por irritación crónica como traumatismos locales, cuerpos extraños y cálculo o ciertos factores que transforman el tejido conectivo de las mucosas en tejido fibroso. Es de crecimiento lento, asintomático y en ocasiones involuciona cuando se eliminan los factores causales. El tratamiento consta de escisión quirúrgica y curetaje de la base de la lesión para evitar recurrencias. Se presenta un caso clínico en el servicio de Estomatología y cirugía oral de una Universidad en Cartagena Colombia, de un paciente de 36 años de edad, masculino y sistémicamente sano con impresión clínica de fibroma periférico odontogénico ubicado en el tercio anterior derecho de paladar duro, ulcerado y asintomático de un año de evolución. Se ejecutan diversos estudios paraclínicos como radiografías panorámicas, periapicales y oclusales para descartar afección a estructuras óseas. Previo a la firma de un consentimiento informado se realizó procedimiento quirúrgico que constó de la escisión quirúrgica de la lesión para posterior análisis histopatológico que confirmó el diagnostico.

Palabras clave: Fibroma periférico odontogénico, hiperplasia fibrosa, escisión quirúrgica.

\section{SUMMARY}

The peripheral odontogenic fibroma is a tumor of the oral submucosa, or periodontal ligament caused by chronic irritation, local trauma, dental calculus foreign agents or certain agents that may transform the connective tissue of the mucous membranes in fibrous tissue. It is like slow growing, asymptomatic and sometimes regress when the etiologic factors are eliminated. Treatment consists of surgical excision and curettage of the base of the lesion to prevent recurrence. In this paper is presented a clinical case in the service of oral surgery and stomatology of a University in Cartagena Colombia, in a 36 years old patient, male and systemically healthy with clinical impression of peripheral odontogenic fibroma located in the anterior third of right palate hard, ulcers and asymptomatic one years of evolution. It was tested different studies, such as panoramic radiographs, periapical and occlusal, for discard condition involving hard tissues. Before signing an informed consent was performed surgical procedure that consisted of surgical excision of the lesion for subsequent histopathological analysis that confirmed the diagnosis.

Key words: Odontogenic tumor, gingival hyperplasia, surgical procedures, operative.

Fecha de recepción: 18 de mayo de 2009.

Aceptado para publicación: 28 de mayo de 2009.

* Odontóloga. Fundación Universitaria San Martín Sede Caribe. Residente de Estomatología y Cirugía Oral. Universidad de Cartagena.

** Odontólogo. Universidad de Cartagena. Profesor titular Universidad de Cartagena.

*** Odontólogo. Universidad de Cartagena. Especialista en Periodoncia. Profesor titular. Universidad de Cartagena.

Rebolledo Cobos M, Cantillo Payares O, Díaz Caballero A. Fibroma periférico odontogénico. A propósito de un caso. Av. Odontoestomatol 2010; 26 (4): 183-187. 


\section{INTRODUCCIÓN}

El fibroma periférico se define como una masa hiperplásica reactiva que surge en la encía adherida y puede derivar del tejido conectivo de la submucosa o del ligamento periodontal. Algunas lesiones corresponden al granuloma telangiectásico "maduro", en el que el tejido de granulación se reemplaza por colágeno $(1,2)$. Es una lesión del tejido fibroso conectivo que a menudo aparece en la mucosa bucal después de un traumatismo la cual puede derivarse del tejido conectivo de la mucosa o del ligamento periodontal. Presenta un proceso crónico subsecuente una lesión en la que hay reparación excesiva y exuberante (tejido de granulación y cicatriz) $(3,4)$. Esta anormalidad se presenta como masas submucosas que pueden ulcerarse de manera secundaria cuando son traumatizadas durante la masticación. Su color varía desde una tonalidad más clara que el tejido circundante (debido al incremento relativo de la colágena) hasta el rojo (por el tejido de granulación abundante y bien vascularizado, puesto que las fibras nerviosas no proliferan con el tejido reactivo hiperplásico estas lesiones son indoloras. Se desconoce cuál es la razón del proceso de reparación exuberante y excesiva, puede aparecer a cualquier edad con predilección el adultos jóvenes (5). Las mujeres sufren estas anomalías con mayor frecuencia que los hombres, la encía anterior a los molares permanentes suele ser la más afectada (6).

El fibroma periférico se presenta como una masa pediculada o sésil de color similar al tejido conectivo circundante. Algunas veces se advierte ulceración sobre la cúspide de la lesión (7). Es infrecuente que provoque erosión del hueso alveolar subyacente $(8,9)$.

Histológicamente el fibroma periférico es una hiperplasia fibrosa focal también conocido como cicatriz hiperplásica. Contiene bastante colágena, es relativamente avascular y en ocasiones muestra infiltrado de células inflamatorias crónicas de leve a moderado. Básicamente es el homólogo gingival del fibroma traumático que se presenta en otras regiones mucosas (10-12). Estas lesiones tienen una presentación clínica muy característica los cual lo hace difícil confundirse sin embargo puede existir cierta superposición con el granuloma telangiectásico y raras veces con el granuloma periférico de células gigantes, cuando estas dos lesiones no tienen un componente vascular prominente $(13,14)$.

El tratamiento de esta lesión debe manejarse mediante escisión quirúrgica que incluya el ligamento periodontal si está afectado. Además cualquier agente etiológico identificable, como cálculo u otro material extraño, debe extirparse. Una escisión quirúrgica hasta el periostio o el ligamento periodontal debe prevenir la recurrencia y posible malignización (15).

\section{DESCRIPCIÓN DEL CASO}

Paciente masculino de 36 años de edad que consulta al departamento de Estomatología y Cirugía Oral de una facultad de Odontología en Cartagena, Colombia, por presentar una lesión tumoral de base pediculada en paladar duro ubicado en lado derecho que se extiende desde incisivo lateral derecho superior hasta el segundo premolar derecho superior el cual es de forma irregular, color rosa, de aproximadamente 3 por 3 centímetros de diámetro, de consistencia firme. En el cuerpo de la lesión presenta una ulceración de 1 por 2 centímetros de diámetro,

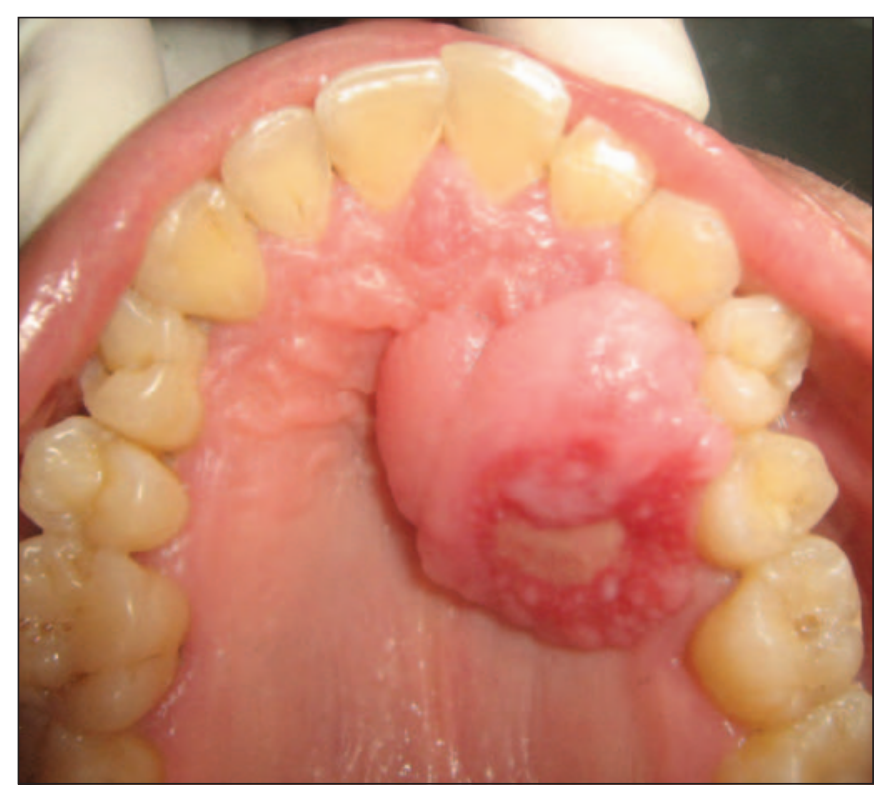

Fig. 1. Imagen clínica tomada a un reflejo de un espejo intraoral de un fibroma periférico odontogénico, se evidencia ulceración en el cuerpo de la lesión. 
con un fondo necrótico y área eritematosa asintomático a la palpación de un año de evolución el cual le ocasiona dificultad para pronunciar fonemas además presenta movilidad dentaria grado 3 en el primer premolar superior derecho que se encuentra asintomático a la palpación. Se realiza radiografía panorámica que evidencia a nivel periodontal de órgano dental 14 lesión radiolúcida, difusa y perdida ósea horizontal avanzada, se procede a realizar radiografía periapical que evidencia la misma lesión periodontal que abarca todo el espacio periodontal con perdida del soporte del mismo por lo cual se recomendó exodoncia quirúrgica del órgano dentario. Se realiza interconsulta con especialista en endodoncia para la realización de pruebas de vitalidad en los órganos dentales circundantes y descartar que la lesión sea de origen de tejido pulpar o endoperiodontal dando como resultado respuesta negativa al frío del órgano dental 14 que supone una necrosis pulpar. De igual forma realizan exámenes de laboratorio como hemograma completo, pruebas de coagulación y glicemia, cuyos resultados estaban dentro de los parámetros normales. Previo al procedimiento quirúrgico al paciente se le comunica las posibles complicaciones que pueden ocurrir durante y después del procedimiento quirúrgico para la firma de un consentimiento informado.

\section{PROCEDIMIENTO QUIRÚRGICO}

Se establecieron medidas de asepsia y antisepsia para someter al paciente a la exodoncia del primer premolar superior derecho aplicándole las técnicas anestésicas; infraorbitarias, dentaria posterior superior derecha y palatina anterior, con lidocaína al $2 \%$ con epinefrina 1:80.000. Se procedió a realizar escisión de la lesión con hoja de bisturí \# 15 para mango de bisturí Bard Parker \# 3, curetaje de la base de la lesión y cauterización con electrobisturí con posterior hemostasia y limpieza del área. Se incluye la muestra en frasco con formol para envío de muestra a patología. Finalmente se coloca una placa de acetato de calibre 0,8 aplicado con cemento quirúrgico para protección y aislamiento del área quirúrgica. Posterior se ordenan antibióticos tipo amoxicilina de 500 mg por 7 días para evitar sobreinfección y nimesulide por 3 días para alivio de sintomatología

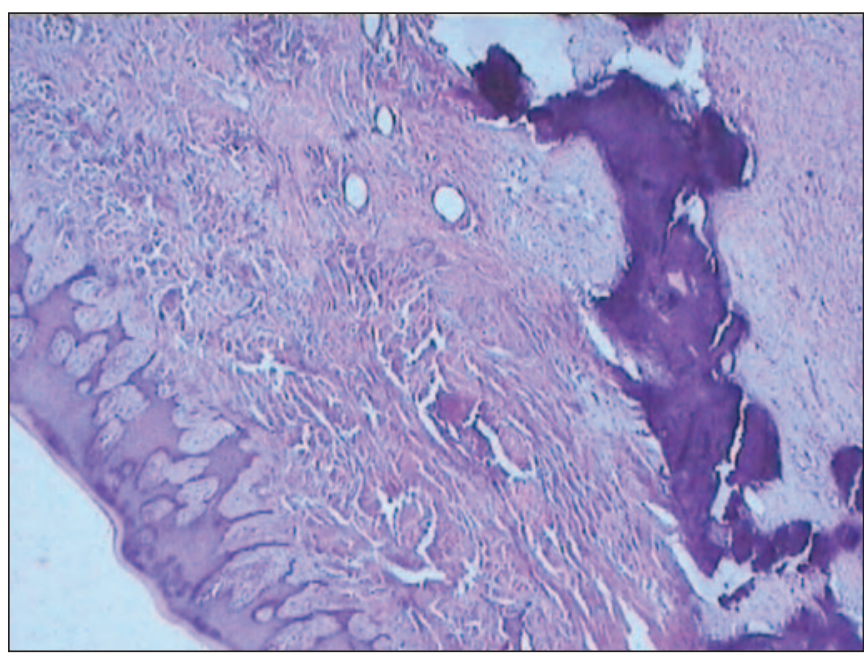

Fig. 2. Imagen histológica que confirma diagnostico de fibroma odontogénico periférico.

dolorosa post quirúrgica. Paciente acude a control postquirúrgico a los 8 días del procedimiento para valoración donde se evidencia buen proceso de cicatrización, ausencia de exudados purulentos o inflamatorios.

\section{INFORME PATOLÓGICO}

Descripción del patólogo se recibe fragmento de tejido blanquecino de aspecto fibroso, duro de 2,8 $\mathrm{cm}$ de diámetro. Se procesa la muestra. Descripción microscópica se observa una lesión constituida por una proliferación de tejido fibroso, con aéreas colagenizadas y centro calcificado, tapizado por epitelio escamoso hiperplásico con ulceración focal e infiltrado inflamatorio severo. No se observan mitosis, atipias ni necrosis.

\section{DISCUSIÓN}

El fibroma periférico es una lesión reactiva focal común la cual es considerada como una neoplasia benigna cuya etiología es bastante polémica pues ésta no se establece con total certeza aunque se cree que tiene una alta relación con traumatismos e irritantes locales los cuales por lo general son crónicos $(1,4)$ coincidiendo con los datos que se obtuvieron del paciente referente al origen de la lesión tumoral 
el cual evidenciaba ser causado por trauma, placa bacteriana y calculo. Dentro los casos reportados en la literatura la presentación de esta patología se da con mayor frecuencia en adolescentes y adultos jóvenes (5) lo cual concuerda con el caso presentado en el cual el paciente presenta una edad de 36 años. En la literatura revisada el fibroma periférico odontogénico presenta prevalencia en pacientes del sexo femenino que en el masculino (6), no coincidiendo con el caso. Las referencias consultadas reportan ulceración de la lesión tumoral cuando se ven expuestas a traumatismos, muy semejante a el caso que reporta ulceración en el cuerpo de la lesión causado por trauma mecánico durante la masticación (7).

Según la frecuencia de aparición el fibroma periférico se localiza comúnmente a nivel mandibular que en el maxilar superior y se observa más en el área de los incisivos, caninos y premolares (4) lo cual es bastante contrastante con el caso ya que este se presenta en el maxilar superior a nivel de los órganos dentarios lateral canino y premolar superior derecho. Esta patología presenta un crecimiento lento progresivo y no es auto resolutivo (12), comparándolo con este caso la lesión continuó su curso de crecimiento tumoral. La forma de diagnosticar con total certeza estas lesiones es a través del examen histopatológico como se ejecuto en este caso puesto que estas lesiones pueden llegar a ser confundidas con otras lesiones de cavidad oral que pueden tener características clínicas y radiográficas similares como lo son fibroma de células gigantes, granuloma periférico de células gigantes, mucocele, tumores de la glándula salival (13). En cuanto al tratamiento de elección de esta patología es la escisión quirúrgica con adecuada eliminación del/los pedículos debido a que es muy poco probable la recurrencia $(14,15)$, por tal motivo en este caso se realizó escisión quirúrgica completa y un buen curetaje del lecho quirúrgico para evitar estas complicaciones.

\section{BIBLIOGRAFÍA}

1. Regezi JA, Courtney RM, Kerr DA. Fibrous lesions of the skin and mucous membranes which contain stellate and multinucleated cells. Oral Surg Oral Med Oral Pathol. 1975 Apr;39(4): 605-14.
2. Manor Y, Merdinger O, Katz J, Taicher S. Unusual peripheral odontogenic tumors in the differential diagnosis of gingival swellings. J Clin Periodontol. 1999 Dec;26(12):806-9.

3. Delbem AC, Cunha RF, Silva JZ, Soubhia AM. Peripheral cemento-ossifying fibroma in child. A follow-up of 4 years. Report of a case. Eur J Dent. 2008 Apr;2(2):134-7.

4. Siar $\mathrm{CH}, \mathrm{Ng} \mathrm{KH}$. Clinicopathological study of peripheral odontogenic fibromas (WHO-type) in Malaysians (1967-95). Br J Oral Maxillofac Surg. 2000 Feb;38(1):19-22.

5. Lownie JF, Altini M, Shear M. Granular cell peripheral odontogenic fibroma. J Oral Pathol. 1976 Sep;5(5):295-304.

6. Lin CT, Chuang FH, Chen JH, Chen CM, Chen YK. Peripheral odontogenic fibroma in a Taiwan chinese population: a retrospective analysis. Kaohsiung J Med Sci. 2008 Aug;24(8):415-21.

7. Ide F, Mishima K, Saito I, Kusama K. Rare peripheral odontogenic tumors: report of 5 cases and comprehensive review of the literature. Oral Surg Oral Med Oral Pathol Oral Radiol Endod. 2008 Oct;106(4):e22-8. Epub 2008 Aug 20.

8. Salum FG, Yurgel LS, Cherubini K, De Figueiredo MA, Medeiros IC, Nicola FS. Pyogenic granuloma, peripheral giant cell granuloma and peripheral ossifying fibroma: retrospective analysis of 138 cases. Minerva Stomatol. 2008 May;57(5):227-32.

9. Zhang W, Chen Y, An Z, Geng N, Bao D. Reactive gingival lesions: a retrospective study of 2,439 cases. Quintessence Int. 2007 Feb;38(2):103-10.

10. Al-Malik MI, Bahatheq MA, Rehbini ZA. Gingival hyperplasia in hyaline fibromatosis-a report of two cases. J Int Acad Periodontol. 2007 Apr;9(2): 42-8.

11. Lukes SM, Kuhnert J, Mangels MA. Identification of a giant cell fibroma. J Dent Hyg. 2005 Summer; 79(3):9. Epub 2005 Jul 1. 
12. Syryñska M. [Extensive angiomatous granuloma of the oral mucosa] Czas Stomatol. 1980 Apr;33 (4):373-5.

13. Badurowa A, Frydecka I. [Telangiectatic granuloma of the oral cavity in chronic thrombopenia] Wiad Lek. 1983 Sep 15;36(18):1541-4.

14. Hubácek M, Dostálová T, Bartonová M, Kozák J, Seydlová M. Giant cell reparative granuloma in the mandible-case report and review of the literature. Acta Chir Plast. 2008;50(2):59-63.
15. Daley TD, Wysocki GP. Peripheral odontogenic fibroma. Oral Surg Oral Med Oral Pathol. 1994 Sep;78(3):329-36.

\section{CORRESPONDENCIA}

Antonio Díaz Caballero

Campus de la Salud. Barrio Zaragocilla

Cartagena. D.T y C. Colombia

Correo electrónico: antoniodiazc@yahoo.com 